\title{
Contribution of hydrocolloids to gelling properties of blue whiting muscle
}

Pérez-Mateos, M.* and Montero, P.

5

Instituto del Frío (CSIC), Dpto. Ciencia y Tecnología de Carnes y Pescados, Ciudad Universitaria s/n, E28040 Madrid, Spain. Fax (34) 915493627

10 Running title: hydrocolloids in blue whiting gels

Key words: gelation, hydrocolloid, blue whiting (Micromesistius poutassou)

15

*miriam@if.csic.es (author to whom correspondence should be addressed) 


\section{Abstract}

Several hydrocolloids (locust bean gum, guar gum, xanthan gum, iota-carrageenan, kappacarrageenan, carboxymethylcellulose and alginate) were added in different concentrations

$5(0.5,1,2,3,4 \%)$ to determine their behaviour as additives in washed blue whiting muscle mince. Higher percentages significantly reduced rheological properties, which in some cases fell to values below that of the control gel (no added hydrocolloids). Water holding capacity, on the other hand, was lowest at low concentrations. Gel colour was virtually unaffected by the presence of different hydrocolloid percentages in the formulation. Discriminant analysis differentiated the various hydrocolloids used, chiefly on the basis of hardness; however, the most influential factor in the concentration of hydrocolloid was breaking force. On this manner, it was defined what properties can be achieved by addition of these ingredients obtaining a variety of characteristics.

\section{INTRODUCTION}

The suitability of the fish protein for gel formation differs according to species, season and place where the fish were caught, and processing and storage conditions. Muscle mince functionality can be altered by addition of gelling agents or aids, particularly polysaccharides. Many hydrocolloids, commonly known as gums, are extracted from seaweed or seeds; they are selected for enhancement of functional properties such as: water holding capacity and rheological properties. However, their action as fibre may affect the nutritional properties as well. They are useful in industrial applications because they are effective at low concentrations. The rheological properties are influenced by the type and concentration of ingredients (1). 
These additives alter gel characteristics in different ways depending on the quality of the myofibrillar protein $(2,3,4)$. When the minced muscle is of high quality, addition of gelling agents or aids can reduce the rheological properties of the product, which is useful for attenuating excessive elasticity and hardness. When quality is low, these additives modify

5 the product's characteristics, enhancing protein functionality, particularly gel forming ability and water holding capacity (5).

There are a number of studies on the interaction on these hydrocolloids with the proteins in model systems $(6,7,8,9)$; however only few studies have been published on the 10 comparative effect of hydrocolloids within the myosystem, and referring to the use of a few hydrocolloids like starches, carrageenans and alginates (4, 10, 11, 12, 13); but scarcely nothing about locust bean gum, guar gum, carboxymethylcelullose nor xanthan gum in fish products.

15 This study provides basic information on functional properties of blue whiting washed mince gels with different hydrocolloids added in various concentrations. It also seeks to determine which act in similar ways and which exhibit unique characteristics. 


\section{MATERIALS AND METHODS}

Blue whiting (Micromesistius poutassou Risso) used in this study was caught off the Cantabrian coast in November. Average size was $22.2 \pm 1.8 \mathrm{~cm}$ and average weight $101.1 \pm$

$22.3 \mathrm{~g}$. Fish were headed, gutted and washed. Skin and bones were removed with a deboning machine (Baader 694, Lübeck, Germany). The resulting mince was washed in a solution of $\mathrm{NaCl}(0.2 \%)$ at $0-3{ }^{\circ} \mathrm{C}$, proportion 3:1 (solution:minced muscle), first with constant stirring for $10 \mathrm{~min}$ then without stirring for another $10 \mathrm{~min}$. After draining, excess water was removed using a screw press (Baader 523, Lübeck, Germany). Sorbitol (4 \%) and tripolyphosphate $(0.2 \%)$ were added as cryoprotectants. The mince was immediately vacuum-packed in bags (Cryovac BB-1, Grace, Spain) and frozen in a plate-freezer (Sabroe SMC, Denmark). The bags were stored at $-80{ }^{\circ} \mathrm{C}$ in a freezer cabinet (Revco ULT, Giralt, Revco Scientific, Inc., Asheville, N.C., USA) in order to minimize alteration during frozen storage up to gel preparation.

Proximate analysis of mince was performed according to AOAC procedures (14) and crude fat by Bligh and Dyer 15). The proximate composition (\%) was: crude protein $13.25 \pm 0.31$, moisture $81.75 \pm 0.71$, crude fat $0.16 \pm 0.03$ and ash $0.40 \pm 0.05$ (analyses do not show added $4.2 \%$ cryoprotectant).

Colour of mince and gels was determined on a HunterLab MiniScan MS/S-4000S (Hunter Associates Laboratory Inc., USA) using the CIE Lab scale (D65/10 ) where $L^{*}, a^{\star}$ and $b^{\star}$ are the parameters that measure lightness, redness and yellowness. The result was the average of six measurements taken at ambient temperature at different points on the sample.

Gel preparation. Washed blue whiting mince was tempered in a chilled room and placed in 
a refrigerated vacuum homogenizer (Stephan UM5, Stephan u. Söhne GmbH \& Co., Germany). It was ground for $1 \mathrm{~min}$ at high speed (start II). Sodium chloride (1\% w/w) in gel (Panreac, Montplet \& Esteban S.A., Barcelona, Spain) was added and homogenized for 3 min at slow speed (start I). Then the hydrocolloid [locust bean gum as Viscogum ${ }^{\circledR}$ BE, guar 5 gum as FFH-200, xanthan gum as Satiaxane ${ }^{\circledR}$ CX90, iota-carrageenan Satiagel ${ }^{\circledR}$ RPT25, kappa-carrageenan as Satiagel $^{\circledR}$ RPT8, sodium carboxymethylcellulose as Tylopur $^{\circledR}$ C10.000 or sodium alginate as Satialgine ${ }^{\circledR}$ S1100 (SKW Biosystems, Rubí, Spain)] was added at different final levels $(0.5,1,2,3$, or $4 \%)$, with crushed ice to give the required final gel moisture (80\%). The homogenate was beaten slowly (start I) for 6 min under vacuum,

10 keeping sample temperature below $10^{\circ} \mathrm{C}$. Batters were stuffed into flexible plastic casings (Krehalon Soplaril, Barcelona, Spain) of $40 \mu \mathrm{m}$ thickness and $3.5 \mathrm{~cm}$ diam. and subjected to heat treatment: $37^{\circ} \mathrm{C}, 30 \mathrm{~min}$ followed by $90^{\circ} \mathrm{C}, 50 \mathrm{~min}$. All the casings were immediately cooled with water at $0{ }^{\circ} \mathrm{C}$ and stored in a cold room at $4{ }^{\circ} \mathrm{C}$ for 24 hours before analysis.

Water holding capacity. About $1.5 \mathrm{~g}$ of sample was placed in a centrifuge tube with two Gilson Pipetman dried pipette filters. A centrifuge (Sorvall RT6000B, Du Pont Co., Delaware, USA) was used at $4000 \mathrm{~g}$ for $15 \mathrm{~min}$ at ambient temperature. Water holding capacity (WHC) was expressed as water retained per $100 \mathrm{~g}$ of water present in the sample prior to centrifuging. All determinations were carried out at least in triplicate.

Folding test (16). A slice $3.5 \mathrm{~cm}$ in diameter and $3 \mathrm{~mm}$ high is folded over twice. If it does not break, a score of 5 is awarded. If it breaks on the second fold, it scores 4 . If a crack shows only on part of the folded edge, it scores 3 . If the crack runs the length of the folded edge, it scores 2. If the slice breaks apart completely, it scores 1.

Puncture test. Samples were removed from their casings, cut $(3.5 \mathrm{~cm}$ diameter, $3 \mathrm{~cm}$ 
height) and tempered at $20^{\circ} \mathrm{C}$. Gels were penetrated to breaking-point using a texturometer (Instron 4501, Instron Engineering Corp., Canton, MA, U.S.A.) with a round-ended stainless steel plunger $(\varnothing=5 \mathrm{~mm})$. Cross-head speed was $10 \mathrm{~mm} / \mathrm{min}$ and a $100 \mathrm{~N}$ load-cell was used. Breaking force $[\mathrm{N}]$, breaking deformation $[\mathrm{mm}]$ and work of penetration $[\mathrm{N} . \mathrm{mm}]$ were determined in the force-deformation curves. All determinations were carried out at least in quadruplicate.

Compression Test (17). Texture Profile Analysis (TPA). Samples (3.5 cm diameter, $3 \mathrm{~cm}$ height) were tempered at $20{ }^{\circ} \mathrm{C}$ and placed on the flat plate of the texturometer. Compression was applied by a cylindrical plunger $(\varnothing=58 \mathrm{~mm})$ adapted to a $5 \mathrm{kN}$ load cell at a deformation rate of $50 \mathrm{~mm} / \mathrm{min}$. On the basis of previous trials to establish a compression limit that would ensure no cracking and recoverability of most samples, it was decided to compress samples to $60 \%$ of their height. In the test, each sample was compressed twice. The parameters determined were hardness [N], adhesiveness [J] and cohesiveness [adimensional]. Elasticity (\%) was determined by stress-relaxation test after 1 min of relaxation. Percent of relaxation was calculate as $Y T=100$. (F0-F1)/F0, where F0 is the force registered at the onset of relaxation immediately after sample compression and F1 is force registered after 1 min of relaxation. Thus, 100-YT is taken as an index of elasticity and is expressed as percent elasticity of the gel. At least four replications of all determinations were performed.

Statistical analysis. One-way analysis of variance was carried out using the BMP computer programme (BMDP Statistical Software, Inc., Cork Technology Park, Cork, Ireland) to determine differences in gel characteristics due to (a) the hydrocolloid concentration and (b) the type of hydrocolloid. All the values of each of the properties determined for three replicates of each gel with each of the hydrocolloids added at each of the five experimental 
concentrations was incluided. The difference of means between pairs was resolved by means of confidence intervals using the Bonferroni test (BMDP 7D). Also, differences of means were determined between pairs of each sample and the control gel (no added hydrocolloid) using a Dunnet test (BMDP 7D). Level of significance was set for $p \leq 0.05$.

5 Multivariate analysis: stepwise discriminant analysis (BMDP 7M) was carried out using the Jackknifed classification. This determines the variables that discriminate groups of gels with respect to the type of hydrocolloid added and with respect to the hydrocolloid concentration.

\section{RESULTS AND DISCUSSION}

In the folding test (Table 1) for gels made with different proportions of the seven target hydrocolloids, there was a significant decrease of the score in the formulations with added carboxymethylcellulose and guar gum. These additives do not themselves gel, but at low concentrations they can reinforce weak areas of the protein network; at higher concentrations; on the other hand, they can interfere in the network formed by the myofibrillar protein, producing brittle gels (3). It is also important to remember that the hydrocolloid and the myofibrillar protein compete for water, to the extent that this may actually prevent proper gelation $(12,13)$. Folding test scores of gels with the other gums (carrageenans, sodium alginate and locust bean gum) remained high, as did those gels containing myofibrillar protein but no hydrocolloid, which scored maximum.

According to Llanto et al (11) the cause of the increased gel forming ability of Alaska pollack surimi when carrageenans are added is the interaction of the sulphate groups of the carrageenan with the myofibrillar protein. On the other hand, other authors (18) failed to improve the low gel forming ability of sardine (Sardina pilchardus) muscle by adding growing concentrations from 1 - $4 \%$ of kappa-carrageenan or up to $2 \%$ alginate. It was only when 2 
$\%$ alginate plus $8 \%$ starch was added that folding test scores improved.

In general breaking deformation (Table 2) decreased significantly as hydrocolloid concentration increased, falling below that of gel without additive $(10.5 \pm 0.6 \mathrm{~mm})$. Breaking deformation was particularly high in gels containing $1 \%$ locust bean gum.

Decrease in breaking deformation values when hydrocolloids are added to the formula has been reported by other authors. Gómez-Guillén and Montero (13) found this when 2 \% iotacarrageenan was added to squid (Dosidicus gigas) mantle gels, and Niwa et al. (19) did so when increasing amounts (4 - $12 \%$ ) of kappa-carrageenan were added to Alaska pollack surimi. In the case of sodium CMC in horse mackerel (Theragra chalcogramma) surimi gels, Niwa et al. (20) attributed it to the fact that with a higher percentage of hydrocolloid (0 - $6 \%)$ more water is held, producing more deformable gels. According to Nakayama et al. (21), on the other hand, breaking deformation increased very slightly with the concentration of kappacarrageenan (0 - $10 \%)$ in a batter made using sardine terrine.

In most cases, breaking force (Table 3) decreased significantly with hydrocolloid concentration, except with kappa-carrageenan. Values were lower than in the hydrocolloidfree gel $(3.9 \pm 0.5 \mathrm{~N})$ even at the lowest concentration $(0.5 \%)$ which would suggest that addition of these polysaccharides interfered with gelation of the myofibrillar protein.

However, the breaking force of the blue whiting gels containing kappa-carrageenan increased considerably with addition of the larger amount $(p \leq 0.05)$. Other authors have reported a noticeable increase in breaking force with kappa-carrageenan concentration in sardine terrine batter (21) and also in Alaska pollack surimi gels (19). Moreover, when alginate was added Nielsen et al. (22) found that breaking force was higher the greater the 
percentage that was added; these authors did however suggest $0.5 \%$ concentration for restructured beef meat products, as these proved more acceptable in sensory terms. Contrasting with this, Gómez-Guillén and Montero (13) found no difference in breaking force between squid (Dosidicus gigas) mantle gels with $2 \%$ added iota-carrageenan and gels

5 made with no added hydrocolloid. Xiong and Blanchard (7) reported that addition of xanthan gum or alginate reduced the breaking force of a gel made from soluble chicken proteins, the more so the higher the concentration; they concluded that this was because both polysaccharides interfered with the protein gel structure. Niwa et al. (20) found that the breaking force of horse mackerel (Theragra chalcogramma) surimi gels decreased with 10 addition of sodium CMC and suggested that this was because gel strength decreased with increasing water-absorbing capacity.

In most of the cases, except locust bean gum and kappa - carrageenan, our own results show that work of penetration (Table 4) was practically double or even more that the overall mean for the group when $0.5 \%$ of hydrocolloid was added; nevertheless, values were lower than in muscle without hydrocolloid $(41.0 \pm 2.5 \mathrm{~N} . \mathrm{mm})$, the similar to results reported above for breaking force and deformation.

The effect of kappa-carrageenan remained constant irrespective of the concentration added, due to the fact that breaking deformation decreased $(p \leq 0.05)$ as breaking force increased $(p \leq 0.05)$. However, Ipsen (8) found that the work of penetration increased in gels made with soy or pea isolate protein when the concentration of kappa-carrageenan was increased; the author suggested that kappa-carrageenan could be an integral part of the protein matrix, or else the main matrix was formed by the hydrocolloid rather than the protein, depending on 25 the ratio of carrageenan to protein. In this connection Gómez-Guillén et al. (23) reported that iota-carrageenan formed an independent network which supported the principal structure 
formed by the fish protein. On the other hand, DeFreitas et al (9) found no indications of specific molecular interaction even although gel strength increased by kappa-carrageenan. They concluded that this was because there was no change in the electrophoretic profile of pork soluble proteins, and also there was no increase in protein-hydrocolloid interaction with protein concentration.

There was also a significant decrease in gel hardness (Table 5) when the hydrocolloid concentration was increased, particularly in the case of xanthan gum and CMC. The reason for this could have been either that the hydrocolloid disrupted the network or that the gel became softer due to the lower protein concentration. Unlike what happened with the penetration properties described above, in many cases the gels were harder than the hydrocolloid-free controls $(119 \pm 9 \mathrm{~N})$.

The presence of kappa-carrageenan significantly increased the hardness of gels, in direct proportion to the amount of kappa-carrageenan added. According to Niwa et al. (10), kappacarrageenan partially contributed to network formation and hence gelation. Also, Foegeding and Ramsey (2) reported that kappa-carrageenan was more effective than iota-carrageenan in increasing the hardness of beef meat gels.

20 The adhesiveness of blue whiting gels was affected by differences in the percentage of added hydrocolloid (Table 6). The values for the hydrocolloid-free gel was about $0.52 \pm 0.04$ J. Only in gels containing xanthan gum and CMC was adhesiveness lower with high concentrations of hydrocolloids. In contrast, adhesiveness increased considerably with kappa-carrageenan, particularly at $4 \%$ concentration. Niwa et al. (10) also reported high 25 adhesive strength between kappa-carrageenan suspension and surface of Alaska pollack surimi gels, which would be physically bound during cooling of the gel. 
The cohesiveness (Table 7) of gels was no greatly affected by addition of locust bean gum, kappa-carrageenan or alginate irrespective of the concentration added as indicate by the overall mean. With all the other gums, however, cohesiveness decreased sharply at

5 concentrations of more than $1 \%(p \leq 0.05)$. When low concentrations of hydrocolloid were added, there was little difference in cohesiveness with respect to hydrocolloid-free gels (55.0 $\pm 0.9 \%$. Given that this property was unaffected by high concentrations of some hydrocolloids and affected by high concentrations of others, the loss of cohesiveness must have been due to the hydrocolloid rather than the reduction of protein concentration in the 10 gel through addition of polysaccharides.

Elasticity (Table 8) was independent of the concentration used in most cases, given that values were very close to the overall mean. There were exceptions, however. When $2 \%$ or more of iota-carrageenan was added, gel elasticity increased dramatically $(p \leq 0.05)$ and was much greater than in the hydrocolloid-free gel (44 $\pm 0.4 \%)$. With xanthan gum on the other hand, gels were less elastic at concentrations higher than $0.5 \%(p \leq 0.05)$, probably due to the large molecular size of the gum; however, at $4 \%$ concentration there was increased elasticity and cohesiveness. The authors can not offer any explanation for this.

20 Addition of hydrocolloid increased water holding capacity (WHC) as compared to hydrocolloid-free gels $(75.68 \pm 1.23 \%)$ (Table 9$)$, thus highlighting their water binding ability. However, hydrocolloid concentrations higher than $1 \%$ did not improve the effect $(p<0.05)$ with the exception of iota-carrageenan, probably because the WHC values were already quite high.

This increase in water binding properties has also been reported by other authors for beef 
meat gels with added iota-carrageenan (2); squid (Dosidicus gigas) mantle gels (13) and sardine (Sardina pilchardus) muscle (4). These last authors pointed to differences in the effect of iota-carrageenan due to the gel forming capacity of the muscle and the amount of $\mathrm{NaCl}$ added to solubilize the myofibrillar protein.

There was no significant difference in water holding capacity between gels with the various concentrations of kappa-carrageenan and the control; however, WHC in this case was considerably lower than in gels with the other hydrocolloids. Da Ponte et al. (24) explained that kappa-carrageenan is quite difficult to hydrate within the myosystem, and they also

10 pointed to the higher WHC of iota-carrageenan. However, DeFreitas et al. (9) reported that the presence of either kappa or iota carrageenan favoured water holding capacity in soluble pork gels. In Alaska pollack surimi gels, again, addition of kappa-carrageenan reduced water loss thanks to its binding action (19). Bernal et al. (25) attributed this behaviour to the fact that carrageenans hold water in the interstitial spaces of the matrix that forms. According to Dexter et al. (12), these differences in the behaviour of carrageenans are due chiefly to the way in which additives are incorporated.

Xiong and Blanchard (7) examined the effect of adding alginate and xanthan gum to a myosystem and found that $0.5 \%$ was one of the best concentrations for water retention in gels made from soluble chicken proteins. With this concentration they achieved gels with around $40 \%$ higher WHC than the same gels without hydrocolloids, because of more entrapment of water by the protein-polysaccharide matrix, but not with higher concentrations. Clarke et al. (26) also suggested that the high effectiveness of alginate could be due not only to its water binding ability, but also to entrapment of water in the protein/hydrocolloid matrix.

$\mathrm{CMC}$ has a clear water binding effect (Table 9). However, when Barbut and Mittal (27) 
added $0.5 \% \mathrm{CMC}$ to frankfurter sausages, they found that less water was retained than without hydrocolloid. These authors suggested that this was probably because CMC enveloped the myofibrillar protein and thus prevented water uptake.

5 Lightness (Table 10) only appeared to be increased by kappa-carrageenan, CMC and alginate, while guar gum tended to darken the gel, although not significantly. None of the other hydrocolloids produced any substantial change in lightness with respect to the gel without additives $(67.71 \pm 2.65)$. Redness (Table 11) increased slightly in gels containing locust bean gum, xanthan gum and alginate; the effect was more intense with high

10 hydrocolloid concentrations. In none of the other cases was there any great change with respect either to the hydrocolloid concentration or the control gel $(-2.46 \pm 0.10)$, this is evident from the overall mean for all concentrations. The overall mean for yellowness (Table 12) was higher than in the hydrocolloid-free gel $(5.45 \pm 0.35)$. This was because the hydrocolloids themselves had a beige colouring which intensified with increased concentration ( $p \leq 0.05$ ), except in the gels containing carrageenans, which exhibited practically no difference with respect to the control.

When carrageenans (both iota and kappa) were added to frankfurter sausages in concentrations ranging from 0.25 to $1 \%$, likewise no colour variations were detected with respect to the carrageenan-free control (28). Carboxymethylcellulose and alginate generally lent a stronger hue, even at low concentrations. Barbut and Mittal (27) similarly found that addition of $\mathrm{CMC}$ to low-fat frankfurters modified the colour.

Subsequent multivariate analysis of all the above results together showed that breaking deformation was the property that best discriminated between gels containing different concentrations of hydrocolloid (statistical $F$ value $=18.3$ ). The other discriminating properties 
were water holding capacity $(F=10.4)$ and, to a lesser extent, adhesiveness $(F=4.5)$ and hardness $(F=4.1)$; in other words, it is mainly these properties that will be altered by variations in concentration. Table 13 shows the number of elements identified with each group according to the concentration used (0.5 - $4 \%$ ) following the Jack-knifed classification. According to this, $81 \%$ of the gels with $0.5 \%$ additive fell within the group; for all other concentrations less than half of the elements entered the corresponding group. For $0.5 \%$ concentration, there were only three cases presenting similar characteristics to gels containing $1 \%$ hydrocolloid, and one case that was similar to gels containing $2 \%$. These cases were (i) locust bean gum: higher breaking deformation, hardness, adhesiveness; (ii) guar gum, higher breaking deformation, lower hardness; (iii) xanthan gum, lower breaking force, work of penetration and hardness, higher elasticity; (iv) kappa-carrageenan, higher adhesiveness and lower water holding capacity. It was concluded from these results that the hydrocolloids had a very different effect at each different concentration, except for $0.5 \%$, at which concentration the patterns of action were more similar.

On the basis of the particular hydrocolloids added, the properties that best classified the gels were hardness, because of the higher F value (61.5), and to a lesser extent gel colour ( $\mathrm{L}^{*}=$ $\left.63.3, a^{*}=23.8, b^{*}=13.7\right)$, breaking deformation $(F$ value $=19.6)$ and elasticity $(F$ value $=$ 12.3). The discrimination among the different formulas was good (see Table 14). Iotacarrageenan produced gels with fully-defined characteristics. For the rest of the formulas, except for gels containing $\mathrm{CMC}$, the probability of characterization as such hydrocolloids was over $85 \%$.

The graphic illustration (Fig. 1) shows that the gels containing each of the seven hydrocolloids fell into two broad groups. In one group were the gels containing xanthan gum, $\mathrm{CMC}$ and alginate, and in the other the gels containing all the other hydrocolloids. In the 
latter group, kappa-carrageenan and locust bean gum are clearly differentiated at either extreme. The cause of this differentiation could be the different types of interaction (electrostatic, ionic) between hydrocolloids and myofibrillar protein $(29 ; 30)$ and/or differences in ability to solubilize or disperse through the protein matrix. It is worth noting here that of all the hydrocolloids, kappa-carrageenan produced the hardest gels and xanthan gum the softest. The weakness of gels with xanthan gum could be due to its high molecular weight, as very large polymers can interfere in the gelling of myofibrillar protein. The gels containing locust bean gum were less light than the gels containing sodium alginate.

10 The addition of hydrocolloids under the present experimental conditions produced a variety of textural characteristics. Gel properties tended to be weakened by increasing concentrations of polysaccharide. However, the degree of modification depended on the particular hydrocolloid and the concentration. Discriminant analysis showed that the seven hydrocolloids tested in gelation of blue whiting muscle all had different characteristics, so that each exhibited a specific action profile. However, the way that these affect gelation will differ according to the intrinsic properties of the muscle proteins.

The debilitation of properties with increased hydrocolloid concentration was possibly due to interference in gel formation by steric hindrance rather than reduction of protein concentration. The enhancement of rheological properties could be due to reinforcement of the protein matrix by the hydrocolloid. The addition of these ingredients to blue whiting muscle with high functional capacity illustrates the many possibilities of achieving specific characteristics by adding specific concentrations of specific hydrocolloids. This opens up a wide range of technological possibilities for the manufacture of fish-based restructured products. Discriminant analysis defines what properties can be achieved by addition of one of these additives. 
Acknowledgements. Thanks to Laura Barrios, Head of the Statistics and Operational Research Service at the Centro Técnico de Informática (CSIC) Madrid for her advice. To the Comision Interministerial de Ciencia y Tecnología (СІСуT) and Comunidad de Madrid (CAM)

for financial support under projects: ALI97-0684, 06G-05396 respectively, and to the Ministerio de Educación y Cultura for the predoctoral fellowship granted to M. P-M at SKW Biosystems-Instituto del Frío (Spain).

\section{LITERATURE CITED}

1. Yoo, B. and Lee, C. (1993) Rheological relationships between surimi sol and gel as affected by ingredients. J. Food Sci. 58(4):880-883.

2. Foegeding, E.A. and Ramsey, S.R. (1987) Rheological and water holding properties of gelled meat batters containing iota-carrageenan, kappa-carrageenan or xanthan gum. J. Food Sci. 52(3):549-553.

3. Lee, C. M.; Wu, M.C. and Okada, M. (1992) Ingredient and formulation technology for surimi-based products. In: Surimi Technology (Lanier, T. And Lee, C., ed.), pp.273-302. New York, USA: Marcel Dekker, Inc. 4. Gómez-Guillén, C. and Montero, P. (1996) Addition of hydrocolloids and non-muscle proteins to sardine (Sardina pilchardus) mince gels. Effect of salt concentration. Food Chem. 56(4):421-427.

4. Gómez-Guillén, C. and Montero, P. (1996). Addition of hydrocolloids and non-muscle proteins to sardine (Sardina pilchardus) mince gels. Effect of salt concentration. Food Chem. 56(4):421-427. 
5. Lee, C.M. (1994) Surimi processing from lean fish. In: Seafoods: Chemistry, processing technology and quality (Shaidi, F. y Bota, J.R., ed.), pp:263-287. London, England: Blackie Academic \& Professional.

5

6. Tolstoguzov, V.B. (1986) Functional properties of protein-polysaccharide mixtures. In Functional properties of food macromolecules (Mitchell, J.R. and Ledward, D.A., eds.), 9:385-415. London, England: Elsevier Applied Science Publishers Ltd.

7. Xiong, Y.L. and Blanchard, S.P. (1993) Viscoelastic properties of myofibrillar proteinpolysaccharide composite gels. J. Food Sci. 58(1):164-167.

8. Ipsen, R. (1997) Uniaxial compression of gels made from protein and kappa-carrageenan. J. Texture Studies 28:405-149.

15

9. DeFreitas, Z; Sebranek, J.G.; Olson, D.G. and Carr, J.M. (1997) Carrageenan effects on salt-soluble meat proteins in model systems. J. Food Sci. 65(3):539-543.

10. Niwa, E.; Wang, T.; Kanoh, S. and Nakayama, T. (1988b) Contribution of gelling substance to muscular protein network structure within kamaboko. Nippon Suisan Gakkaishi 54(6):989-992.

11. Llanto, M.G.; Bullens, C.W.; Modliszewski, J.J. and Lee, C.M. (1990) The function of carrageenan in surimi and surimi-based seafood analogues. In: IFT Annual Meeting, 25 Anaheim, CA, USA. 
12. Dexter, D.R.; Sofos, J.N. and Schmidt, G.R. (1993) Quality characteristics of turkey bologna formulated with carrageenan, starch, milk and soy protein. J. Muscle Foods 4:207-223.

13. Gómez-Guillén, C. and Montero, P. (1997) Improvement of giant squid (Dosidicus gigas) muscle gelation by using gelling ingredients. Z. Lebensm. Unters. Forsch. 204:379-384.

14. AOAC. (1984) Official Methods of Analysis; Association of Official Analytical Chemistry, Washington, DC, USA.

15. Bligh, E. G. and Dyer, W.J. (1959) A rapid method of total lipid extraction and purification. Can. J. Biochem. Phys. 37, 911-917.

16. Suzuki, T. (1981) Fish and krill protein: processing technology, pp.132. London, England: Applied Science Publishers LTD.

17. Bourne, M.C. (1982) Principles of objective texture measurement. In Food Texture and Viscosity: Concept and Measurement (Stewart, G.F.; Schweigert, B.S. and Hawthorn, J., eds.), 45-117. New York, USA: Academic Press.

18. Montero, P.; Pardo, M.V.; Gómez-Guillén, M.C. and Borderías, J. (1992) Hidrocoloides como potenciadores de la gelificación del músculo picado de sardina. In: /l Congreso Internacional de Química "Ciencia y Tecnología de los Alimentos": Industria alimentaria y distribución"; Burgos, Spain.

19. Niwa, E.; Wang, T.; Kanoh, S. and Nakayama, T. (1988a) Strengthening effect of the 
various natural high polymers on the elasticity of the kamaboko. Nippon Suisan Gakkaishi 54(5):841-844.

20. Niwa, E.; Tsujimoto, K. and Kanoh, S. (1992) Kamaboko gel-strengthening effect of polyuronides and other polysaccharides. Nippon Suisan Gakkaishi 58(1):85-88.

21. Nakayama, T.; Kashiwagi, Y.; Kanoh, S. and Niwa, E. (1988) Manufacturing of sardine terrine by addition of carrageenan. Nippon Suisan Gakkaishi 54(1):123-128.

22. Nielsen, H.T.; Høegh, L. and Møller, A.J. (1996) Effect of a kappa carrageenan/locust bean gum mixture on bind and cooking loss in high mannuronate alginate restructured beef. J. Muscle Foods 7:413-424.

23. Gómez-Guillén, C.; Solas, T.; Borderías, J. and Montero, P. (1996) Effect of heating temperature and sodium chloride concentration on ultrastructure and texture of gels made from giant squid (Dosidicus gigas) with addition of starch, $\mathrm{l}$-carrageenan and egg white. Z. Lebensm. Unters. Forsch. 202:221-227.

24. da Ponte, D.J.B.; Herst, J.M.; Roozen, J.P. and Pilnik, W. (1985) Effects of different types of carrageenans and carboxymethyl celluloses on the stability of frozen stored minced fillets of cod. J. Food Tech. 20:587-598.

25. Bernal, V.M.; Smajda, C.H.; Smith, J.L. and Stanley, D.W. (1987) Interactions in protein/polysaccharide/calcium gels. J. Food Sci. 52(5):1121-1125,1136.

26. Clarke et al. (1988) cited in Nielsen et al. (1996). 
27. Barbut, S. and Mittal, G.S. (1996) Effects of three cellulose gums on the texture profile and sensory properties of low fat frankfurters. Int. J. Food Sci. Technol. 31:241-247.

5 28. Bloukas, J.G.; Paneras, E.D. and Papadima, S. (1997) Effect of carrageenan on processing and quality characteristics of low-fat frankfurters. J. Muscle Foods 8:63-83.

29. Dickinson, E. and Pawlowsky, K. (1996) Effect of high-pressure treatment of protein on the rheology of flocculated emulsions containing protein and polysaccharide. J. Agric. Food Chem. 44:2992-3000.

30. Rourke, T.J.; Clarke, A.D.; Bailey, M.E. and Hedrick, H.B. (1997) Ionic interactions in algin/calcium/myofibrillar protein gels. J. Muscle Foods 8:33-46. 